\title{
Incidência e controle químico da ferrugem da goiabeira em diferentes épocas de poda na região norte do Espírito Santo
}

\author{
Marlon Vagner Valentim Martins ${ }^{1 *}$, Luiz Augusto Lopes Serrano ${ }^{1}$, Inorbert de Melo Lima², \\ Erik Bravim de Oliveira ${ }^{3}$
}

\section{RESUMO}

No norte do Estado do Espírito Santo, vem sendo observada a ocorrência crescente da ferrugem (Puccinia psidii G. Winter) nos pomares de goiabeira, ocasionando a queda de frutos novos e o declínio na produção. Este trabalho teve como objetivo avaliar tratamentos com fungicidas no controle da ferrugem em goiabeiras 'Paluma' podadas em diferentes épocas do ano. Foram realizados três experimentos, em delineamento em blocos ao acaso, com diferentes épocas de poda de frutificação (janeiro; maio e outubro) e quatro tratamentos fungicidas (I- testemunha - aplicação de água, II- oxicloreto de cobre, III- tebuconazole e IV-tebuconazole + oxicloreto de cobre). Observou-se que, quando a poda foi realizada em janeiro, houve as maiores incidências máxima e final da doença, acarretando menor número de frutos por planta. Dentre os fungicidas testados, tebuconazole isolado ou em mistura com oxicloreto de cobre foram os mais eficientes em controlar a doença nas três épocas de poda, inclusive na época de maior incidência da doença. Quatro pulverizações com tebuconazole, isolado ou em mistura com o oxicloreto de cobre, foram suficientes para minimizar os danos causados pela ferrugem da goiabeira.

Palavras-chave: Psidium guajava L., Puccinia psidii G. Winter, poda de frutificação, fungicidas.

\section{ABSTRACT}

\section{Incidence and chemical control of guava rust in different pruning times in the north of Espírito Santo, Brazil}

In the north of Espírito Santo State, Brazil, increasing occurrence of rust (Puccinia psidii G. Winter) has been observed in guava trees, causing fruit drop and yield losses. The objective of this work was evaluate the incidence and chemical control of guava rust in 'Paluma' guava trees pruned in different seasons. Three experiments were carried out in a randomized complete block design, with three different pruning times (January; May and October) and four fungicide spraying treatments (I - untreated check, II - copper oxychloride, III - tebuconazole and IV - tebuconazole + oxychloride copper). Plants pruned in January showed the highest maximum and final guava rust incidences and smallest number of fruits per plant. Regardless of pruning time, the effective rust control occurred in plants sprayed with tebuconazole and tebuconazole plus copper oxychloride fungicides. Four sprayings with tebuconazole pure or mixed with copper oxychloride were sufficient to mitigate the damage caused by guava rust.

Key words: Psidium guajava L., Puccinia psidii G. Winter, fruit setting, pruning, fungicide.

\footnotetext{
Recebido para publicação em 27/07/2011 e aprovado em 28/03/2012

${ }^{1}$ Engenheiro-Agrônomo. Doutor, Empresa Brasileira de Pesquisa Agropecuária (EMBRAPA/CNPAT), Rua Dra. Sara Mesquita, 2270, Pici, 60511-110, Fortaleza, Ceará, Brasil. valentim@cnpat.embrapa.br; serrano@cnpat.embrapa.br (*autor para correspondência).

2 Engenheiro-Agrônomo. Mestre, Instituto Capixaba de Pesquisa, Assistência Técnica e Extensão Rural (INCAPER), Centro Regional de Desenvolvimento, Rural Nordeste, Rodovia BR 101 Norte, km 151, Caixa Postal 62, 29900-970, Linhares, Espírito Santo, Brasil. inorbert@incaper.es.gov.br

${ }^{3}$ Engenheiro-Agrônomo. Bolsista. Instituto Capixaba de Pesquisa, Assistência Técnica e Extensão Rural - INCAPER, Centro Regional de Desemvolvimento Rural Nordeste, Rodovia BR 101 Norte, km 151, 29900-970, Linhares, ES, Brasil. erik.bravim@ hotmail.com
} 


\section{INTRODUÇAO}

O cultivo da goiabeira (Psidium guajava L.) é tradicional no Estado do Espírito Santo e, nos últimos anos, vem-se tornando importante para os agricultores, em vista da instalação, na região, de novas indústrias processadoras de polpa e produtoras de sucos. Desse modo, em 2003, foi implantado em Pedro Canário, região Norte Capixaba, o "Pólo de goiaba para a industrialização", com o plantio de 300 ha de goiabeira 'Paluma' (Serrano et al., 2007), fato que propiciou o aumento da produção estadual de 6.900 toneladas, em 2003, para 10.063 toneladas, em 2009 (IBGE, 2012).

Na região sudeste do Brasil, em condições naturais, o surgimento de novas brotações na goiabeira ocorre no início do período chuvoso (setembro a outubro), sendo que os brotos novos que surgem apresentam gemas vegetativas e floríferas. Entretanto, o surgimento destes brotos não é uniforme, razão pela qual a florada ocorre durante o período de setembro a novembro e, a maturação dos frutos (safra principal), no período de janeiro a março (Serrano et al., 2008). Por meio da prática da poda de frutificação, associada à irrigação e à adequada adubação, há a possibilidade de se produzirem frutos ao longo de todo o ano, inclusive na entressafra (abril a novembro), quando os preços são mais elevados (Serrano et al., 2007). Além disso, a colheita da goiaba nesta época é considerada ideal pelas indústrias processadoras de polpas do Estado do Espírito Santo, uma vez que não coincide com o pico das safras de manga e maracujá.

Nos primeiros anos da introdução do "Pólo de goiaba", constatou-se crescente incidência da ferrugem da goiabeira, sendo esta doença considerada relevante, uma vez que a ocorrência de clima favorável e o cultivo de uma variedade susceptível têm desencadeado o surgimento de epidemias durante as épocas de produção.

A ferrugem da goiabeira é causada pelo fungo Puccinia psidii G. Winter. A doença torna-se severa sob condições de alta umidade relativa e temperatura média em torno de $22^{\circ} \mathrm{C}$, condições estas que ocorrem na região. Esse fungo infecta tecidos jovens da planta, principalmente os botões e os frutos novos, causando abortamento de flores, necrose em brotações novas e queda acentuada de botões e frutos. $\mathrm{O}$ avanço da doença é limitado com o amadurecimento dos tecidos, condições verificadas em frutos com diâmetro equatorial acima de 3,0 cm (Goes et al., 2004; Martins et al., 2011).

Os fatores epidemiológicos da doença e os fenológicos da cultura são importantes para o manejo da ferrugem. Porém, o controle químico é ainda considerado o principal método de controle (Martins et al., 2011).

Na região, a ocorrência da ferrugem foi observada nos pomares de goiabeira 'Paluma' (Serrano et al., 2007) e o controle foi baseado em pulverizações semanais com fungicidas protetores, a base de cobre, e sistêmicos. No controle de diferentes espécies de ferrugens e em diferentes regiões do Brasil, fungicidas protetores e sistêmicos têm sido utilizados com sucesso (Garçon et al., 2004; Carvalho et al., 2008; Dalla Pria et al., 2008; Wanyera et al., 2009; Buck et al., 2010). Vários trabalhos demonstram eficiência de fungicidas no controle da ferrugem causada por P. psidii nas culturas do eucalipto (Ruiz et al., 1987; Zauza et al.,2008; Masson et al., 2011;) e da goiabeira (Ferrari et al., 1997; Goes et al., 2004; Martins et al., 2011). Entretanto, não há informações sazonais da ocorrência e sobre o manejo da ferrugem da goiabeira na região norte Capixaba, o que contribui para o aumento das pulverizações em qualquer época do ano.

Este trabalho teve como objetivo avaliar a incidência e o controle químico da ferrugem da goiabeira, por meio de fungicidas recomendados pela Produção Integrada de Goiaba (INMETRO, 2011), em diferentes épocas de poda, na região norte do Espírito Santo.

\section{MATERIAL E MÉTODOS}

O experimento foi realizado em um pomar irrigado de 8,0 ha de goiabeiras 'Paluma', com 3,5 anos de idade, em espaçamento $6,5 \mathrm{~m}$ x 4,0 m, localizado no distrito de Cristal do Norte, município de Pedro Canário, região norte do

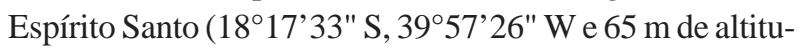
de). A região, segundo Köppen, é tropical chuvosa, caracterizada pela ocorrência de uma estação seca durante o ano (maio a setembro).

Foram realizados três experimentos, em delineamento em blocos ao acaso, com diferentes épocas do ano, de acordo com as datas da poda de frutificação. As podas foram realizadas em 16/01/08 (época I); 13/05/08 (época II) e 22/10/08 (época III), épocas estas que possibilitam a colheita dos frutos na entressafra (julho, dezembro e abril, respectivamente).

Em cada época, foram avaliados quatro tratamentos fungicidas para o controle da ferrugem da goiabeira: I- TEST - tratamento testemunha com pulverização de água; II- OC - pulverização de fungicida a base de oxicloreto de cobre $\left(\mathrm{Cu}_{2} \mathrm{Cl}(\mathrm{OH})_{3}\right)$ a $2.400 \mathrm{mg}$ de ingrediente ativo (i.a.) $\mathrm{L}^{-1}$; III- TEB - pulverização do fungicida tebuconazole ( $150 \mathrm{mg}$ de i.a. $\left.\mathrm{L}^{-1}\right)$; e IV- TEBOC - pulverização da mistura de tebuconazole $\left(150 \mathrm{mg}\right.$ de i.a. $\left.\mathrm{L}^{-1}\right) \mathrm{e}$ oxicloreto de cobre (2.400 $\mathrm{mg}$ de i.a. $\mathrm{L}^{-1}$ ).

As podas de frutificação foram realizadas de acordo com Serrano et al. (2007) e as adubações conforme Natale et al. (2003). Em cada época de poda de frutificação, foi selecionada uma linha de plantas do pomar, sendo escolhidas 16 plantas semelhantes quanto ao porte (altura e diâmetro de copa), estados nutricional e sanitário, e potencial produtivo. Cada linha de plantas foi dividida em 
quatro blocos com quatro plantas cada, as quais receberam os quatro tratamentos para o controle da ferrugem da goiabeira. Cada repetição foi constituída de uma planta de goiabeira.

A partir do início do surgimento dos botões florais, entre 56 e 77 dias após a poda (Serrano et al., 2008), foram avaliadas as incidências de botões e,ou, frutos doentes nos quatro pontos cardeais da planta, totalizando 500 botões e,ou, frutos por planta. A incidência da ferrugem foi avaliada em intervalos de 7 a 14 dias, com seis, dez e sete avaliações para as épocas I, II e III, respectivamente.

As pulverizações foram realizadas com pulverizador costal motorizado (Yamaha LS-937 ${ }^{\circledR}$ ), no período matutino, sendo aplicados $1,5 \mathrm{~L}$ da calda por planta. Os fungicidas foram aplicados inicialmente quando foram detectados de 5 a $10 \%$ de botões doentes nas parcelas experimentais, e reaplicados em intervalos de 7 a 14 dias até os frutos tornarem-se resistentes à infecção de $P$. psidii - diâmetro equatorial acima de 3,0 cm.

Os dados de campo foram analisados quanto às incidências máxima (ymáx) e final (yfinal) de frutos doentes. A área abaixo da curva de progresso da ferrugem (AACPF) foi obtida por meio do programa AVACPD (Torres \& Ventura, 1991). Por fim, foi determinado o número de frutos colhidos por planta.

Os valores médios de temperatura, umidade relativa e precipitação, entre a poda e a última avaliação, foram de $25,1^{\circ} \mathrm{C}, 79 \%$ e $594 \mathrm{~mm}$ (época I); $22,1^{\circ} \mathrm{C}, 73 \%$ e $85 \mathrm{~mm}$ (época II); e 25, $1^{\circ} \mathrm{C}, 76 \%$ e $760 \mathrm{~mm}$ (época III) (SIAG, 2009).

Para verificar a interação dos fatores época de poda de frutificação e tratamentos fungicidas, foi realizada análise de variância conjunta dos experimentos. As médias obtidas dos tratamentos foram comparadas pelo teste de Tukey, a 5\% de probabilidade. Todas as análises foram realizadas pelo programa Statistical Analysis System (SAS).

\section{RESULTADOS E DISCUSSÃO}

As épocas de poda de frutificação, os tratamentos fungicidas e a interação entre estes influenciaram todas as variáveis estudadas (Tabela 1). Nas três épocas de poda, constatou-se que a ferrugem foi importante doença na região de Pedro Canário, ES. Verificou-se que tanto os botões florais quanto os frutos novos foram susceptíveis à ferrugem nos períodos de avaliação.

A maior incidência de frutos com ferrugem e a maior AACPF foram observadas no ciclo da poda realizada em janeiro, fato que, provavelmente, ocasionou menor número de frutos por planta (Tabela 1). No período de pleno florescimento (março), ocorreu grande volume de precipitação e decréscimo na temperatura média, comparativamente aos meses anteriores (janeiro e fevereiro) (SIAG, 2009). Esses fatores climáticos associados podem ter beneficiado a epidemia de ferrugem.
Nos ciclos das podas de maio e de outubro também foi constatada a ocorrência da doença na época de florescimento (julho e janeiro, respectivamente), porém em menor incidência, quando comparada com o ciclo da poda de janeiro, o mais favorável (Tabela 1 e Figuras 1, 2 e 3). No mês de julho, praticamente não houve chuva na região e nos meses de janeiro e fevereiro foram constatadas as maiores médias diárias de temperaturas (SIAG, 2009). Na região produtora de goiaba no norte do Estado do Rio de Janeiro, Rocabado (2003) também observou menor incidência da ferrugem da goiabeira nos meses mais quentes do ano (janeiro e fevereiro).

No ciclo da poda realizada em janeiro, a aplicação do tebuconazole (TEB) e da mistura do tebuconazole com o oxicloreto de cobre (TEBOC) propiciou melhor controle da doença, uma vez que as incidências máxima e final da doença e a AACPF foram inferiores às do tratamento com a aplicação do oxicloreto de cobre (OC) (Tabela 1). A aplicação do oxicloreto de cobre isolado conferiu menor incidência da doença, quando comparada com o tratamento testemunha (TEST), evidenciando algum efeito de controle da doença.

Nos ciclos das podas realizadas em maio e outubro, foi observada menor incidência da doença e, por isso, houve menor diferenciação entre os tratamentos com fungicidas. Nestas épocas, o tratamento com OC resultou em incidências semelhantes a TEB e TEBOC (Tabela 1). Ressalta-se, porém, que, nestas mesmas épocas, o resultado do tratamento com OC não se diferenciou do da TEST. Apenas os tratamentos químicos com TEB e TEBOC resultaram em incidência final da doença menor que a testemunha.

Quanto ao número de frutos por planta, somente no ciclo da poda de janeiro, em que ocorreu maior incidência de ferrugem, foi observada diferença entre as plantas testemunhas e as dos tratamentos com fungicidas (Tabela 1). Semelhantemente aos resultados das incidências da doença no ciclo da poda em janeiro, os números de frutos por planta, nas plantas pulverizadas com TEB e TEBOC foram superiores aos das plantas pulverizadas com OC. As plantas pulverizadas com OC apresentaram número de frutos semelhante ao das plantas testemunhas.

Nos ciclos das podas de maio e de outubro, não foram observadas diferenças no número de frutos por planta, entre as plantas tratadas e não tratadas com fungicidas (Tabela 1). Foi observado, nestas épocas, que a incidência final da ferrugem nas plantas do tratamento testemunha foi entre 44 e $69 \%$ menor que quando comparada com a incidência do ciclo da poda de janeiro. Assim, a quantidade de frutos novos que possam ter caído decorrente da ferrugem pode não ter alterado o índice final de pegamento dos frutos da goiabeira, que está em torno de apenas $20 \%$ (Serrano et al., 2008). 
Segundo os resultados apresentados, tem-se que, tanto em épocas de alta ou de baixa incidência da ferrugem da goiabeira, o tratamento químico com tebuconazole isolado ou em mistura com oxicloreto de cobre proporciona controle satisfatório da doença. Já, em épocas de menor incidência da doença, o oxicloreto de cobre isolado pode ser utilizado no manejo integrado da doença, pelo fato de apresentar controle semelhante ao do tebuconazole. Ademais, seu uso torna-se importante para se minimizar o risco do surgimento de resistência aos fungicidas sistêmicos, inibidores da biossíntese de ergosterol (DMIs), como o tebuconazole (Forcellini et al., 2001).

Em quase todas as épocas de poda de frutificação, verificou-se que o fungicida OC manteve a epidemia praticamente estável durante o ciclo de produção da goiabeira (Figuras 1, 2 e 3). No ciclo da poda de janeiro, a taxa de progresso da ferrugem em frutos mostrou-se negativa durante todo o período de avaliação (Figura 1). Esses resultados estão de acordo com os de outros autores, que demonstraram a importância do OC no controle da ferrugem, nas culturas da goiabeira (Ferrari et al. 1997; Goes et al. 2004; Martins et al., 2011), do eucalipto (Ruiz et al., 1987) e, também, no patossistema cafeeiro e Hemileia vastatrix (Garçon et al., 2004; Carvalho et al., 2008). Embora tenha tido eficiência, deve-se atentar para o fato de este fungicida causar efeito fitotóxico nos frutos, se pulverizado quando estes estão com diâmetro equatorial acima de $3 \mathrm{~cm}$ (Goes et al., 2004; Rezende et al., 2008).

As pulverizações com TEB e TEBOC foram eficientes já a partir da primeira pulverização, ocorrida aos dez dias antes do início das avaliações nas plantas podadas em janeiro (Figura 1). O fungicida TEB foi eficiente no controle da ferrugem mesmo após a ocorrência da infecção, fato que demonstra sua ação curativa daquelas infecções já iniciadas nos botões e frutos da goiabeira. Esses resultados estão de acordo com os apresentados por Zauza et al. (2008) que demonstraram o efeito curativo desse fungicida em infecções de $P$. psidii em eucalipto.

O TEB também teve efeito curativo após penetrar em folhas de eucalipto e inibir o desenvolvimento de Cylindrocladium candelabrum (Ferreira et al., 2006). Segundo Zauza et al. (2008), além do efeito curativo, o TEB apresenta ação protetora quando aplicado antes das infecções de $P$. psidii em eucalipto. Masson et al. (2011) relataram também a eficiência deste fungicida, com efeito curativo e erradicante de $P$. psidii. Goes et al. (2004) também constataram a eficiência de TEB no controle de $P$. psidii. Em outros patossitemas, este fungicida também foi eficiente em controlar a ferrugem do alho e do trigo, causadas pelo fungos Puccinia porri e Puccinia graminis tritici, respectivamente (Dalla Pria et al., 2008; Wanyera et al., 2009). 

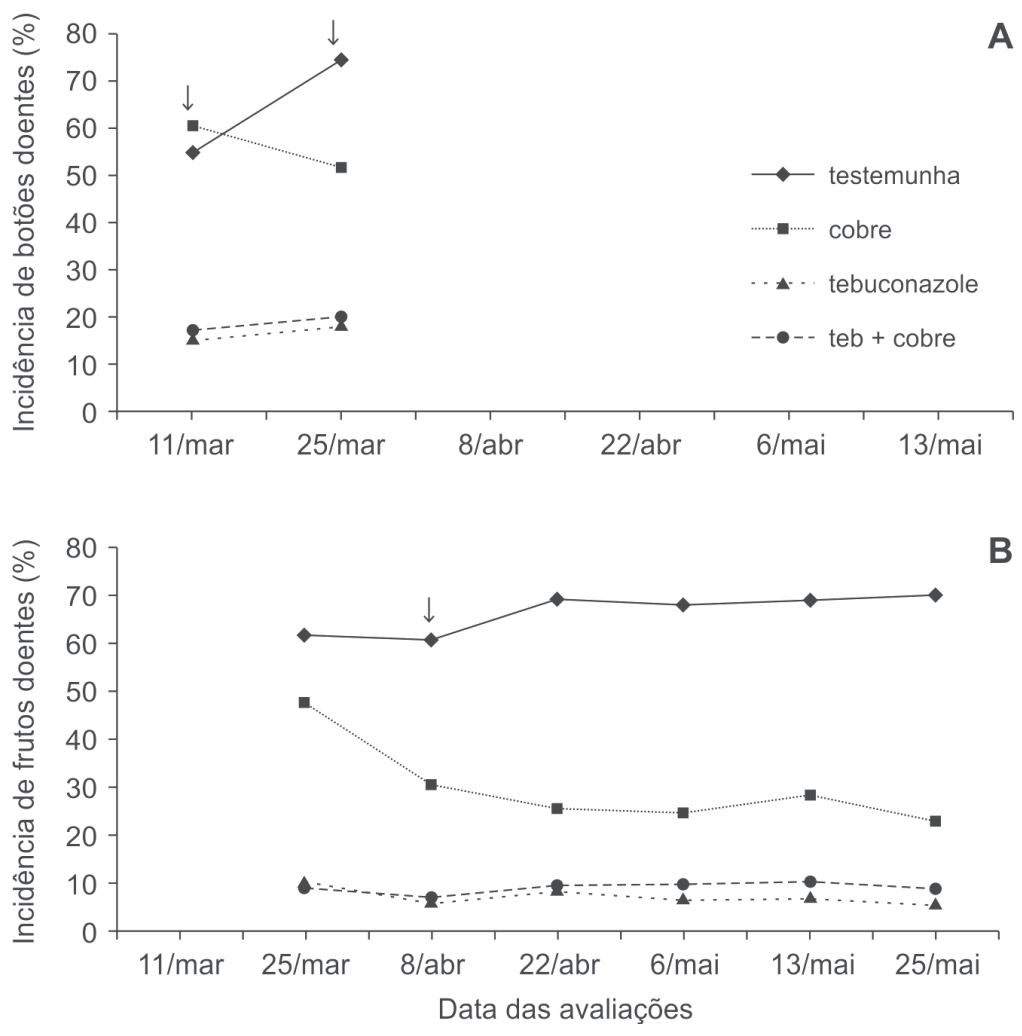

Figura 1. Progresso da ferrugem em botões (A) e em frutos (B) da goiabeira 'Paluma' submetida à poda em janeiro/2008 (época I), em Pedro Canário, ES. A $1^{\mathrm{a}}$ pulverização ocorreu a dez dias antes da $2^{\mathrm{a}}$. As setas da esquerda para a direita correspondem à $2^{\mathrm{a}}, 3^{\mathrm{a}}$ e $4^{\mathrm{a}}$ pulverizações nos dias $11 / 03,25 / 3$ e $08 / 4$ respectivamente.
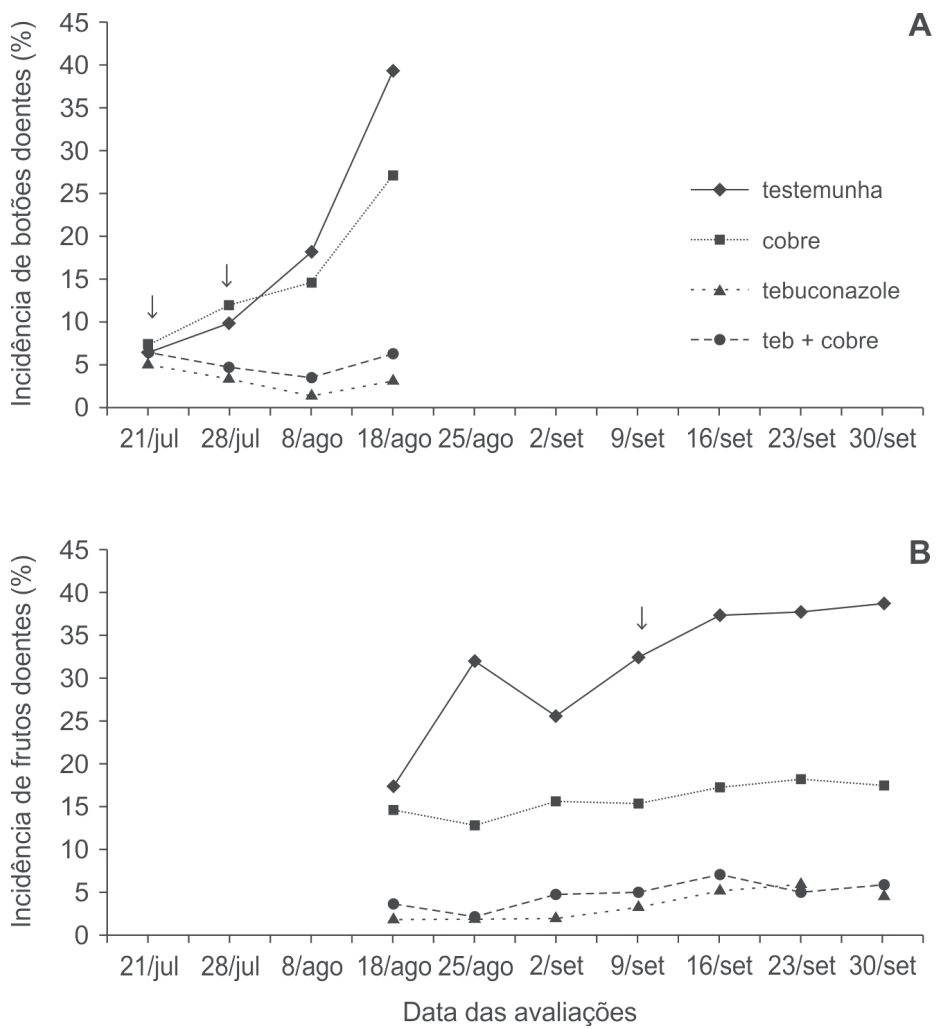

Figura 2. Progresso da ferrugem em botões (A) e em frutos (B) da goiabeira 'Paluma' submetida à poda em maio/2008 (época II), em Pedro Canário, ES. As setas da esquerda para a direita correspondem à $1^{\mathrm{a}}, 2^{\mathrm{a}}$ e $3^{\mathrm{a}}$ pulverizações no dias 21/7, 28/7 e 09/9, respectivamente.

Rev. Ceres, Viçosa, v. 59, n.2, p. 178-184, mar/abr, 2012 

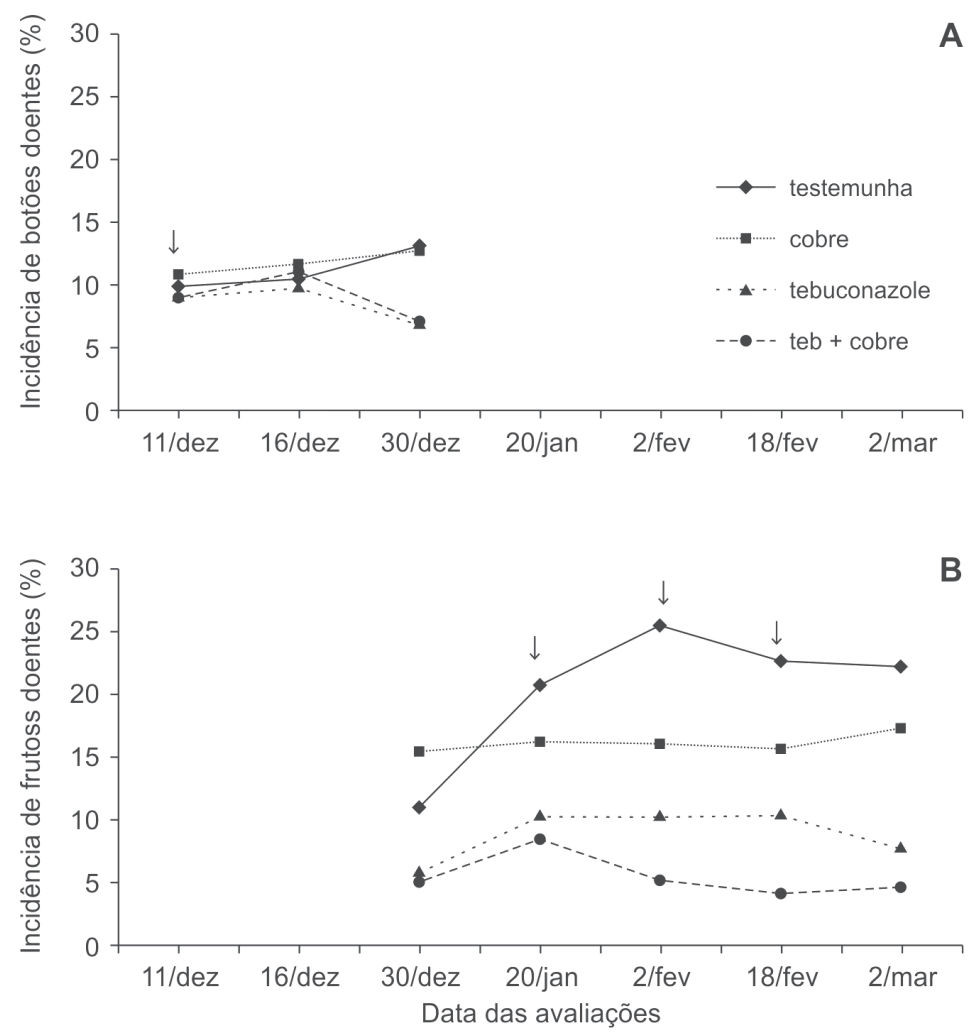

Figura 3. Progresso da ferrugem em botões (A) e em frutos (B) da goiabeira 'Paluma' submetida à poda em outubro/2008 (época III), em Pedro Canário, ES. As setas da esquerda para a direita correspondem à $1^{\mathrm{a}}, 2^{\mathrm{a}}, 3^{\mathrm{a}}$ e $4^{\mathrm{a}}$ pulverizações no dias 11/12, 20/01, 02/2 e $18 / 2$, respectivamente.

Neste trabalho, constatou-se também que o fungicida foi eficiente no controle da ferrugem, não apenas pela sua ação curativa, mas por apresentar ação protetora em condições de campo. Também foi observado provável efeito erradicante desse fungicida sobre as pústulas e lesões de ferrugem em frutos, as quais, após pulverização, não mais produziram esporos e cicatrizaram. Frutos com lesões cicatrizadas podem ser comercializados para a indústria de processamento.

Os resultados também corroboram os apresentados por Martins et al. (2011), em cujo trabalho as aplicações de TEB foram importantes em reduzir a incidência de frutos doentes e estabilizar a taxa de progresso da ferrugem da goiabeira.

É importante salientar que, no ciclo da poda de janeiro, mesmo ocorrendo $34 \%$ de botões doentes antes da primeira pulverização, o fungicida TEB foi eficiente em reduzir o progresso da doença, mesmo com as quatro pulverizações deste experimento, ante as cinco empregadas por Martins et al. (2011) no norte do Estado do Rio de Janeiro.

Nos ciclos das podas realizadas em maio e outubro, a ferrugem foi monitorada desde o início do surgimento dos botões florais e, quando sua incidência atingiu 8 e 10\%, respectivamente, pulverizou-se pela primeira vez. Notouse que a incidência final de frutos com ferrugem permane- ceu no mesmo patamar de quando as plantas foram pulverizadas com TEB e TEBOC (Figuras 2 e 3 ).

Dessa forma, os tratamentos fungicidas com tebuconazole, isolado ou em mistura com oxicloreto de cobre, ambos registrados para cultura da goiabeira, foram eficientes no controle da doença na região norte Capixaba e abrem perspectivas para a produção de goiabas, nos moldes da produção integrada (PIF Goiaba).

\section{CONCLUSÕES}

O ciclo de produção de goiaba a partir da poda de frutificação, realizada em janeiro, favorece o surgimento da epidemia de $P$. psidii, para as condições de cultivo da goiabeira na região norte Capixaba;

Os fungicidas à base de tebuconazole, isolado ou em mistura com o oxicloreto de cobre, são eficientes para o controle da ferrugem da goiabeira;

Quatro pulverizações são suficientes para controlar a doença em épocas de maior epidemia da ferrugem.

\section{AGRADECIMENTOS}

À Fundação de Amparo à Pesquisa do Espírito Santo, pelo financiamento do projeto; ao Instituto Capixaba de Pesquisa, Assistência Técnica e Extensão Rural

Rev. Ceres, Viçosa, v. 59, n.2, p. 178-184, mar/abr, 2012 
(INCAPER), pelo apoio estrutural; ao produtor rural Carlito Corrêa Nascimento, pela disponibilidade da área; e ao pesquisador da EMBRAPA, Adroaldo Guimarães Rossetti, pela contribuição na análise estatística.

\section{REFERÊNCIAS}

Buck J, Wise KA \& Weibo D (2010) Effect of rust-symptom application of fungicides on urediniospore production by Puccinia triticina on wheat and Puccinia hemerocallidis on daylily. Plant Disease, 95:325-330.

Carvalho VL, Cunha RL, Guimarães PTG \& Carvalho JPF (2008) Influência do zinco na incidência de doenças do cafeeiro. Ciência e Agrotecnologia, 32:804-808.

Dalla Pria M, Zagonel J \& Fernandes EC (2008) Controle de ferrugem na cultura do alho com uma nova mistura de fungicidas. Horticultura Brasileira, 26:268-270.

Ferrari JT, Nogueira EMC \& Santos AJT (1997) Control of rust (Puccinia psidii) in guava (Psidium guajava). Acta Horticulturae, 452:55-58

Ferreira EM, Alfenas AC, Maffia LA \& Mafia RG (2006) Eficiência de fungicidas sistêmicos para o controle de Cylindrocladium candelabrum em eucalipto. Fitopatologia Brasileira, 31:468475 .

Forcellini CA, Goellner CI \& May-de-Mio LL (2001) Resistência de fungos a fungicidas. Revisão Anual de Patologia de Plantas, 9:339-381

Garçon CLP, Zambolim L, Mizubuti ESG, Vale FXR \& COSTA, H (2004) Controle da ferrugem do cafeeiro com base no valor da severidade. Fitopatologia Brasileira, 29:486-491.

Goes A, Martins RD \& Reis RF (2004) Efeito de fungicidas cúpricos, aplicados isoladamente ou em combinação com mancozeb, na expressão de sintomas de fitotoxicidade e controle da ferrugem causada por Puccinia psidii em goiabeira. Revista Brasileira de Fruticultura, 26:237-240.

IBGE - Instituto Brasileiro de Geografia e Estatística - Produção Agrícola Municipal. Disponível em: < http// www.sidra.ibge.gov.br>. Acessado em: 25/01/2012.

INMETRO - Normas Técnicas Específicas para a Produção Integrada De Goiaba - Ntepi-Goiaba. Disponível em: <http:// www.inmetro.gov.br>. Acessado em 02/03/2011.

Martins MVV, Silveira SF, Maffia LA, Rocabado JMA \& MussiDias V (2011) Chemical control of guava rust (Puccinia psidii) in the Northern Region of Rio de Janeiro State, Brazil. Australasian Plant Pathology, 40:48-54.

Masson MV, Moraes WB, Matos WC, Alves JM \& Furtado EL (2011) Eficiência e viabilidade econômica do controle químico da ferrugem do eucalipto em condições de campo. Summa Phytopathologica, 37:107-112.

Natale W (2003) Calagem, adubação e nutrição da cultura da goiabeira. In. Rozane DE, Couto FAA \& EJA (eds.) Cultura da goiabeira: tecnologia e mercado. Viçosa, UFV, p.303-331.

Rezende AMFA, Tomita CK \& Uesugi CH (2008) Fungicidas cúpricos, cloretos de benzalcônio e composto bioativo líquido (Bokashi): fitotoxicidade e controle da seca dos ponteiros causada por Erwinia psidii em goiabeiras. Tropical Plant Pathology, $33: 288-294$.

Rocabado JMA (2003) Epidemiologia e patogênese da ferrugemda-goiabeira, causada por Puccinia psidii. Tese de Doutorado. Universidade Estadual do Norte Fluminense 'Darcy Ribeiro' UENF, Campos dos Goytacazes, 119p.
Ruiz RAR, Alfenas AC, Ferreira FA \& Zambolim L (1987) Fungicidas protetores e sistêmicos para o controle da ferrugem do eucalipto, causada por Puccinia psidii. Revista Árvore, 11:56-65.

Serrano LAL, Marinho CS, Ronchi CP, Lima IM, Martins MVV \& Tardin FD (2007) Goiabeira 'Paluma' sob diferentes sistemas de cultivo, épocas e intensidades de poda de frutificação. Pesquisa Agropecuária Brasileira, 42:785-792.

Serrano LAL, Marinho CS, Lima, IM, Martins MVV, Ronchi CP \& Tardin FD (2008) Fenologia da goiabeira 'Paluma' sob diferentes sistemas de cultivos, épocas e intensidades de poda de frutificação. Bragantia, 67:701-712.

SIAG - Sistema de Informações Agrometeorológicas do Espírito Santo. Disponível em: <www.siag.incaper.es.gov.br>. Acessado em 16/06/2009.

Torres JC \& Ventura JA (1991) AVACPD: Um programa para calcular a área e o volume abaixo da curva de progresso da doença. Fitopatologia Brasileira, 16:52.

Wanyera R, Macharia JK, Kilonzo SM \& Kamundia JW (2009) Foliar fungicides to control wheat stem rust, race TTKS (Ug99), in Kenya. Plant Disease, 93:929-932.

Zauza EAV, Couto MMF, Maffia LA \& Alfenas AC (2008) Eficiência de fungicidas sistêmicos no controle da ferrugem do Eucalyptus. Revista Árvore, 32:829-835. 